\title{
CATALYST PROCESSING AND RECYCLING
}

\author{
Jakub Kovalčík \\ Institute of Logistics and Transport, Technical University of Košice, Park Komenského 14, 04200 Košice, Slovak \\ Republic, EU, jakub.kovalcik@tuke.sk (corresponding author) \\ Martin Straka \\ Institute of Logistics and Transport, Technical University of Košice, Park Komenského 14, 04200 Košice, Slovak \\ Republic, EU, martin.straka@tuke.sk
}

\section{Peter Kačmáry}

Institute of Logistics and Transport, Technical University of Košice, Park Komenského 14, 04200 Košice, Slovak Republic, EU, peter.kacmary@tuke.sk

\section{Tomáš Pavlík}

Faculty BERG, Technical University of Košice, Park Komenského 19, 04200 Košice, Slovak Republic, EU, tomas.pavlik@tuke.sk

Keywords: statistics, auto catalyst, environment, precious metals

Abstract: Discussed auto catalysts contain interesting quantities of platinum noble metals, palladium and rhodium according to the type of auto catalyst, thereby becoming a possible source of these metal aims to acquaint themselves with catalysts in general, their history and last but not least the possibilities of processing and obtaining noble metals for further use. The article deals with knowledge at the theoretical level of use of methods in processing depleted catalysts. It is pyrometallurgical and hydrometallurgical methods. The platinum group metals (PGMs) palladium, platinum, and rhodium represent the key materials for automotive exhaust gas treatment. Since there are currently no adequate alternatives, the importance of these metals for the automotive industry is steadily rising. The high value of PGMs in spent catalysts justifies their recycling. The state-of the-art technology is to melt the ceramic carrier and collect the precious fraction in a liquid metal bath. As the feed material has quite high melting points, huge amounts of energy are required for this process. Hydrometallurgical treatments of the spent catalysts offer the possibility to recycle the PGMs with less energy and time demands. Moreover, automotive catalysts contain further valuable materials to improve the exhaust gas treatment. These compounds, like cerium oxide, cannot be recovered in pyrometallurgical processes.

\section{Introduction}

Since the 1950s, all major car manufacturers began to devote to reducing the proportion of toxic substances in the exhaust gases and it is that road transport is involved in more than $90 \%$ in the overall environmental pollution. The effort of car manufacturers for reduction in emission production is supported by legislation since the late 1960s is supported by legislation when the first emission standard has been adopted by the exhaust limit values in the California In Europe, the first emission standard began in 1971, when it is clear that the share of products based on power equipment based on the combustion process will also have an increasing trend to completely exhaust fossil energy resources, the only way to reduce the share of toxic substances in Flue gas is to streamline combustion process and simultaneously eliminate the toxic impact of imperfect combustion products by chemical procedures. The catalyst life is estimated at $128,000 \mathrm{~km}$, depending on how combustion engine use. Since the catalyst contains noble platinum metals whose occurrence in the environment is limited, at the end of its life, platinum metals are obtained from the exhausted car catalysts. In addition to positives that brings the catalyst in reducing the amount of exhalation in the air, it also has a negative impact on the environment in the form of release of platinum metal particles. The high price of these metals led to intensive research activities to substitute them. Nowadays no cheaper materials are available that offer similar properties for these kinds of catalytic reactions. Based on the facts that every new car has to be equipped with a catalytic converter and the number of car registrations is steadily increasing, the demand for platinum group metals (PGMs), particularly platinum, will grow continuously. Taking into account that one catalytic converter contains approximately from $1 \mathrm{~g}$ up to $15 \mathrm{~g}$ of PGMs, it could be easily supposed that this field represents the main application for palladium, platinum and rhodium

The recycling itself for dealing with the amount of authors. Nowadays this is a very busy theme with respect to the environment. Authors Alexandra Končalová and Alena Dubcová are focused on the development of recycling in the waste management concentrate the development of waste recovery in the Slovak Republic with emphasis on its regional differences [1]. Authors DengyeXun, Han Hao, Xin Sun, Zongwei Liu, Fuquan Zhao at article titled End-of-life recycling rates of platinum group metals in the automotive industry: Insight into regional disparities [2] talk about the unavailability of 


\section{CATALYST PROCESSING AND RECYCLING}

Jakub Kovalčík; Martin Straka; Peter Kačmáry; Tomáš Pavlík

natural resources in relation to precious metals and the need for recycling materials that contain these rare metals. They are also dealing with regional differences in recycling materials that mentioned rare metals contain. Authors George Asimellis, Nikolaos Michos, Ioanna Fasaki, Michael Kompits, in article titled Platinum group metals bulk analysis in automobile catalyst recycling material by laser-induced breakdown spectroscopy [3] have developed an application to detect noble metals in the catalyst. The application is based on a laser-induced spectroscopy. A true catalytic catalyst form in powder form was used to develop the application. This method requires approximately 1.5 minutes of the sample examination. The accuracy of noble metals can determine with a 3 percent deviation. Authors Yunji Ding and colleagues in article Highly efficient recovery of platinum, palladium, and rhodium from spent automotive catalysts via iron melting collection [4] designed a high-efficient technology to restore platinum, palladium, and rhodium by iron collection. Thanks to the same cubic structure focused on the structure, it is used as a collector because iron and noble metals can form a continuous solid solution. Another authors from recycling car catalysts are Lucas Gonçalves da Silva, Rodolpho Faria Dias de Almeida, Vinícius Marinho Silva Faustino, Pedro Américo Almeida Magalhãe Júnior [5]. Many authors deal with different options and recycling methods of car catalysts in their studies. In article Platinum Recovery from Hydrometallurgical Residue of Waste Automotive Catalysts Processing by High-Temperature Smelting Process [6], authors Chuan Liu, Shuchen Sun describe the hydrometallurgical method of recycling at high temperature. This method is also described in our article.

\section{Auto catalyst history}

Although the environmental pollution affects a number of factors such as. Discharge of harmful substances to air from individual production undertakings, oil mining, agriculture, waste disposal and so on. With the development of the automotive industry, the production of exhaust exhausts discharged into air is gradually increased, and the environmental pollution was increasingly in increasingly. For this reason, a solution started to remove this pollution. At the same time, the effort to reduce the environmental pollution legislatively treated through emission standards. The development and installation of a technical equipment called the catalyst into the exhaust system was achieved reduction in emission by means of transport. In the 1970s, he started to install the car catalyst. In 1974, started in the UK first production of automotive catalysts in the world. A year later, the first US catalysts appeared. In 1976, as the first used today used a three-way catalyst with a lambda probe was Volvo. In 1985, the first cars with exhaust catalysts, at that time used in the US for several years, receives to Europe [7].

\subsection{The importance and division of automotive catalysts}

Automobile catalyst is a technical device mounted in the exhaust system of the car. It is defined as a substance that reduces the activation energy needed to respond and accelerates it. After completion of the reaction, the catalyst has the original chemical composition of the catalyst to convert toxic agents such as carbon monoxide, $\mathrm{HC}_{\mathrm{x}}$ hydrocarbons, and $\mathrm{NO}_{\mathrm{x}}$ nitrogen oxides, resulting from an imperfect combustion process in the engine cylinders, almost harmless substances such as carbon dioxide $\mathrm{CO}_{2}$, nitrogen $\mathrm{N}_{2}$ and water steam $\mathrm{H}_{2} \mathrm{O}$, with noble metal platinum, rhodium and palladium that have catalytic effects. The outer side catalyst reminds the conventional exhaust silencer. The interior construction of the catalyst is very different from structurally. It consists of a steel shell, a ceramic, or a metal carrier on which noble metals are applied as platinum, rhodium, palladium, metal fibre and the lambda probe are also part of the catalyst, serving the correctness of the mixed fuel mixture (Figure 1). The most important part of the catalyst is its active part, ceramic or metal carrier on which are applied - steamed noble metals Platinum, Rhodium, Palladium [7].

\section{Division of catalysts:}

- Oxidizing - when oxidation is changed - oxidizes $\mathrm{CO}_{2}$ and $\mathrm{C}_{\mathrm{x}} \mathrm{H}$ to $\mathrm{H} 2 \mathrm{O}$ and $\mathrm{CO}_{2}$.

- Reducing - nitrogen $\mathrm{NO}_{\mathrm{x}}$ ingredients are reduced to $\mathrm{N}_{\mathrm{x}}$ and $\mathrm{CO}_{2}$ during combustion, exhaust gases are introduced back into combustion space. Cooled are bred back into the combustion chamber and thereby reducing $\mathrm{N}_{\mathrm{x}}$ emission.

- Three-way - It can dispose of all three harmful substances $\mathrm{CO}, \mathrm{C}_{\mathrm{x}} \mathrm{H}_{\mathrm{y}} \mathrm{NO}_{\mathrm{y}}$.

- Self-regenerating - the most unique type with perovskite structure [8].

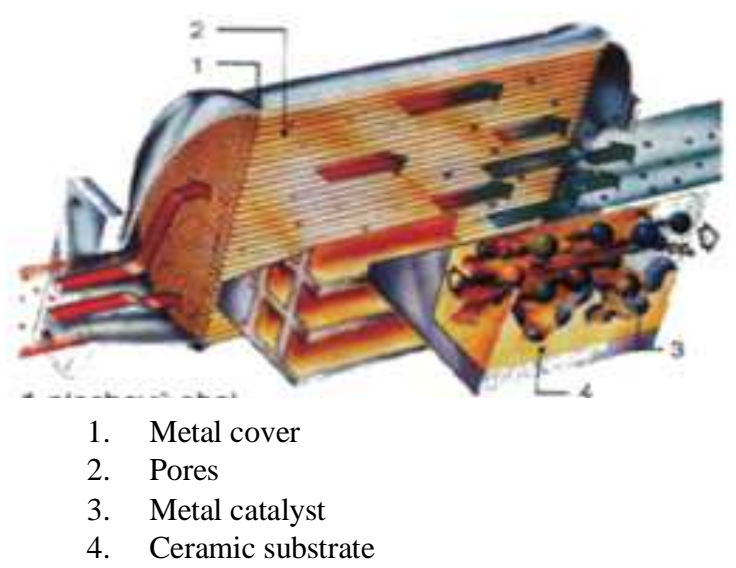

Figure 1 View of the catalyst [8]

\section{Methods of processing used catalysts}

Stronger legislation Ticking emission limits of exhaust gas vehicles and automotive industry status Guarantee 


\section{CATALYST PROCESSING AND RECYCLING}

Jakub Kovalčík; Martin Straka; Peter Kačmáry; Tomáš Pavlík

stable interest in new catalysts, and also increasing interest after platinum, rhodium and palladium. For the same reasons, it is also interested in amortized catalysts. The catalyst operating temperature is about $250^{\circ} \mathrm{C}$. The metal carrier base catalysts reach this temperature under a short period of time than ceramic catalysts. This is an important factor because when the catalyst is heated to operating temperature, a large amount of exhaust emissions is produced. At extreme temperatures, metal catalysts have better physical and chemical properties than ceramic catalysts. The unique cylindrical and corrugated construction allows them to better withstand excessive vibration and constant repetition of temperature changes.

Along with stricter exhaust emission limits, the content of platinum, palladium and rhodium in automotive catalytic converters is also increasing. The two-way catalyst contains $0.04 \%$ by weight of platinum and $0.015 \%$ by weight of palladium, the three-way catalyst contains $0.08 \%$ by weight of platinum, $0.04 \%$ by weight of palladium and $0.005-0.007 \%$ by weight of rhodium. palladium and rhodium economically significant. Properly organized, the collection and recycling of auto catalysts can be, and indeed are, a significant secondary source of platinum, palladium, and rhodium in advanced western economies [9].

Figure 2 shows a general technological procedure for the technological processing of catalysts.

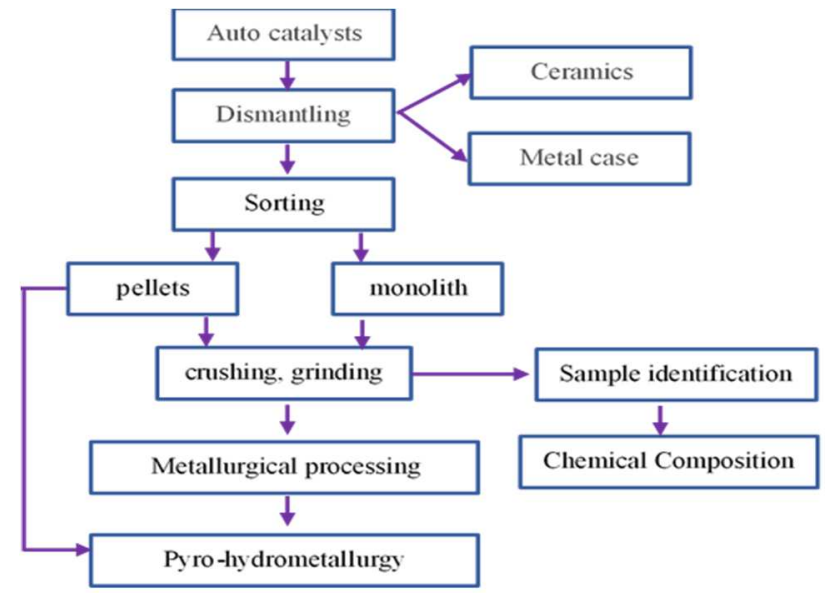

Figure 2 Exhausted catalyst processing technology scheme [8]

We can divide the processing of exhausted catalysts into two basic methods:

1. Pyrometalurgical method.

2. Hydrometalurgical method.

\section{Pyrometallurgical method:}

There are many ways to recover precious metals from depleted auto-catalysts. Pyrometallurgical methods for the recycling of platinum metals use as a collector the collection of metals, especially iron and copper. The pyrometallurgical method can be divided into 2 parts:

\section{- $\quad$ Plasma melting:}

In the recycling of catalysts by plasma melting, the catalyst is subjected to crushing and grinding, the batch is supplemented with a mixture of $\mathrm{Fe}+\mathrm{FeO}$, melted in a plasma furnace at a temperature exceeding $2000^{\circ} \mathrm{C}$. This is followed by the separation of the molten slag and the next iron-containing phase with concentrated platinum metals. The iron alloy is then dissolved in an aqueous solution of sulfuric acid with aeration. Undissolved platinum metals are filtered off, the filtrate is neutralized.

\section{- Melting in EOP (electric arc furnaces):}

When melting with copper, the catalyst is, after mechanical treatment, including crushing and grinding, together with copper carbonate, silica, calcium oxide and iron oxide in a special electric furnace at temperatures of 1600-1800 degrees Celsius.

The melt is divided into slag and an alloy of platinum metals with copper. The copper alloy is dissolved in an aqueous sulfuric acid solution using air as an oxidant. Copper carbonate is recovered by precipitation with sodium ash. The cooled solution is filtered.

In recent years, pyrometallurgical methods have focused on smelting with copper as the collecting metal and on plasma smelting technology, which uses iron as a collector. It is necessary to use hydrometallurgical processes to obtain precious metals from an alloy with a collecting metal. We can therefore speak of these recycling technologies as combined processes. The process of recycling platinum metals pyrometallurgically is shown in Figure 3 [10].

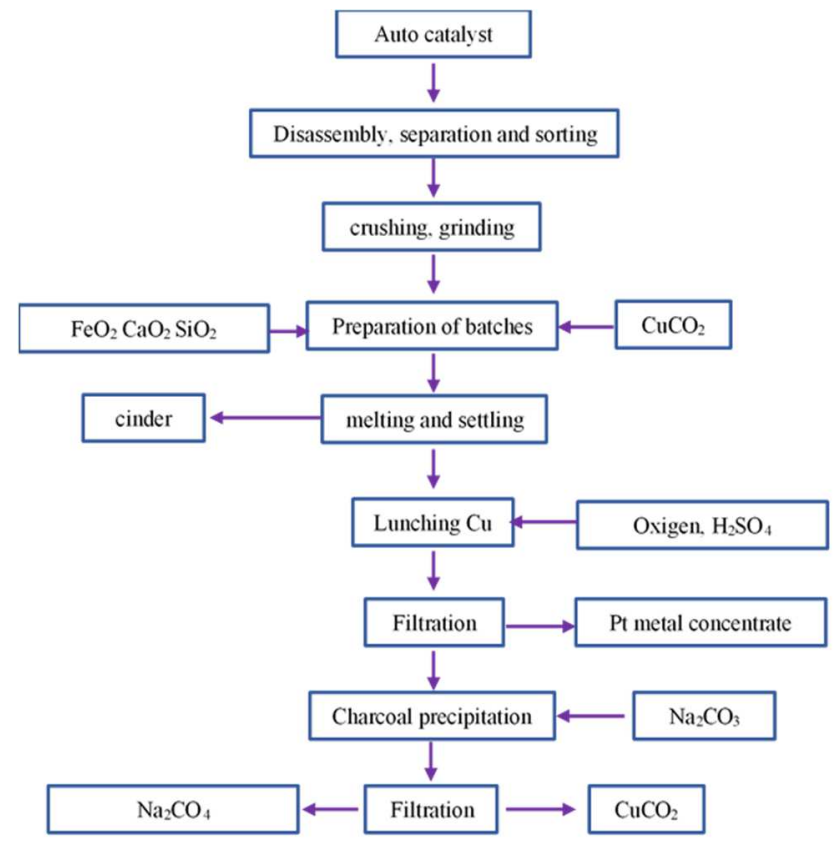

Figure 3 Recycling diagram for pyrometallurgical procedure [8] 


\section{CATALYST PROCESSING AND RECYCLING}

Jakub Kovalčík; Martin Straka; Peter Kačmáry; Tomáš Pavlík

\section{Hydrometallurgical methods:}

A number of processes have been designed and patented for the processing of auto catalysts. In hydrometallurgical processing, the noble metals leached with salivic acid and subsequently the leachate containing noble metals are purified by chemical precipitation or cementation. The pure leachate is further processed into metal, into a chemical concentrate of precious metals or by other methods (adsorption, ion exchange, extraction). The disadvantages of hydrometallurgical methods are the loss of metals, especially rhodium in wastewater, and the problem is also the formation of aluminium sulphate as a by-product.

The hydrometallurgical treatment of catalysts is preceded (during the treatment of catalysts by acid leaching and chlorination) by calcination at a temperature of approx. $500-600{ }^{\circ} \mathrm{C}$, where organic residues of petrol and oils are burned. Unburned carbon residues of gasoline and oils stick to the pores of the catalysts, preventing the penetration of leaching solutions into the pores and thus reducing the yield of the obtained metals.

The catalyst in the form of pellets is dissolved in sulfuric acid after mechanical treatment. to obtain an almost neutral solution (catalyst is in excess). The leachate from the leaching of catalysts is treated by cementation with aluminium in the presence of tellurium dioxide. The resulting aluminium sulphate is used to treat water. The solid phase from the cementation is mixed with insoluble residues from the primary leaching and dissolved in $\mathrm{HCl}+$ CL2. Platinum metals are deducted from this solution by sulphur dioxide in the presence of Te, which acts as a collector. The reduced solution is filtered hot, the platinum metals and, after cooling, the lead chloride are filtered off. Hydrochloric acid $\mathrm{HCl}$ is recycled. The procedure for treating the catalyst by acid leaching is shown in FIG

Hydrometallurgical methods include acid leaching of whole pellets, or selective leaching of noble cocci. This is followed by refining of the extract and its processing, most often by pressure reduction or precipitation. They are among the most excited. In addition to the above-diluted conventional technological procedures, research work is aimed at discovering alternative methods. Fast, accurate and correct quantitative determination of platinum metals in automotive catalysts is a must for laboratory researchers and industrial practitioners [11].

\section{Import and demand of valuable metals in the world}

The metals from the platinum group are used in many different industries, for example dental, jewellery, and chemicals. Nevertheless, the most important use is based on their catalytic properties. Approximately $50 \%$ of platinum and palladium are used as automotive and industrial catalysts. In case of rhodium, an even higher percentage (around 80-90\%) is used as an alloying element in the active layer of different catalysts. The high required amount of $300-900 \mathrm{~kg}$ of treated ore to obtain approximately $1 \mathrm{~g}$ of PGM is responsible for the high prices. On average, the contents in the ore of $\mathrm{Pt}$ and $\mathrm{Pd}$ are 5-10 times higher than $\mathrm{Rh}$ and $\mathrm{Ru}$ and around 50 times higher than Ir and Os.

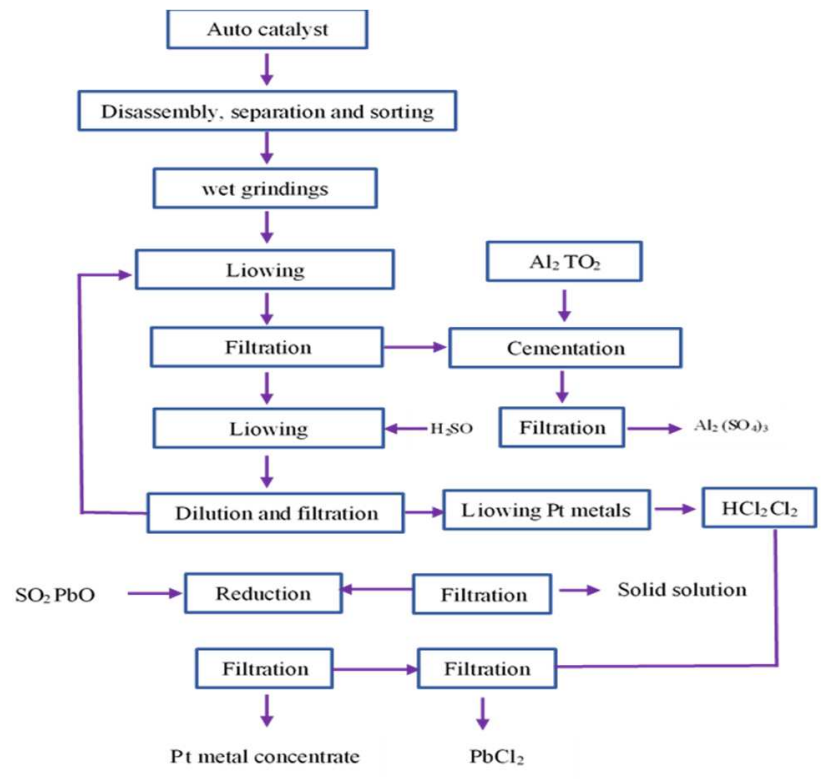

Figure 4 Hydrometallurgical method processing scheme [8]

Additionally, the regional limitation of ore bodies leads to a strong dependence on mainly South Africa and Russia as PGM suppliers. Based on the strong discrepancy in supply and demand of PGM's around the world, recycling of catalysts is mandatory and meaningful from the ecological and economical point of view. Based on the high prices of PGM, the industry is forced to improve the efficiency of catalysts, which is done by improving the wash coat technology. By using rare-earth elements, like cerium oxide, the surface can be increased and the ability to supply oxygen is secured. As a side effect, cerium as an additional critical element is introduced into the recycling circuit of catalytic converters, forming a further valuable component and forming a major challenge for common pyrometallurgical converter recycling [12].

First, like shown in Fig. 5, a strong discrepancy of suppliers (mainly Africa and Russia) and consumers (Europe, China, Japan, and North America) exists. Worldwide reserves of PGM are estimated by the U.S. Geological Survey (USGS) in 2013 to be present to $95 \%$ in South Africa, $1.6 \%$ in Russia, and the remaining $2.8 \%$ in the rest of the world underlining the strong dependence on Africa's supply. Due to the presence of permafrost soil in Russia and deep mines in Africa, the processing of the ore is cost intensive. A peak in demand cannot easily be compensated, for instance in the case of Russia, because their PGMs are produced as a by-product of nickel. Russia would have to increase their production of nickel, leading to a higher supply, and thus to a lower price for their main product (nickel), to increase the PGM production [13]. 


\section{CATALYST PROCESSING AND RECYCLING}

Jakub Kovalčík; Martin Straka; Peter Kačmáry; Tomáš Pavlík
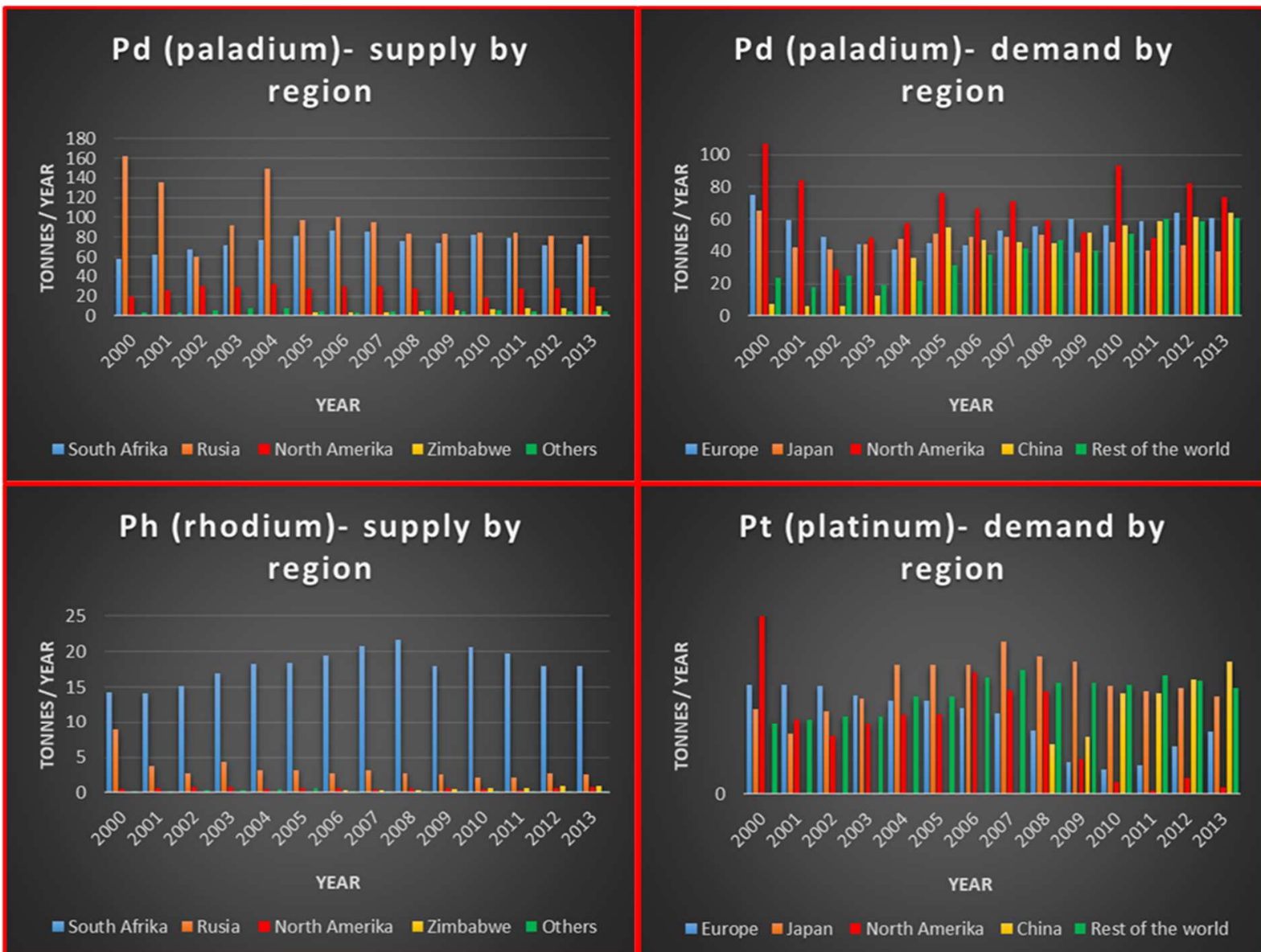

nSouth Afrika $n$ Rusia North Amerika $\quad$ Zimbabwe $\quad$ Others

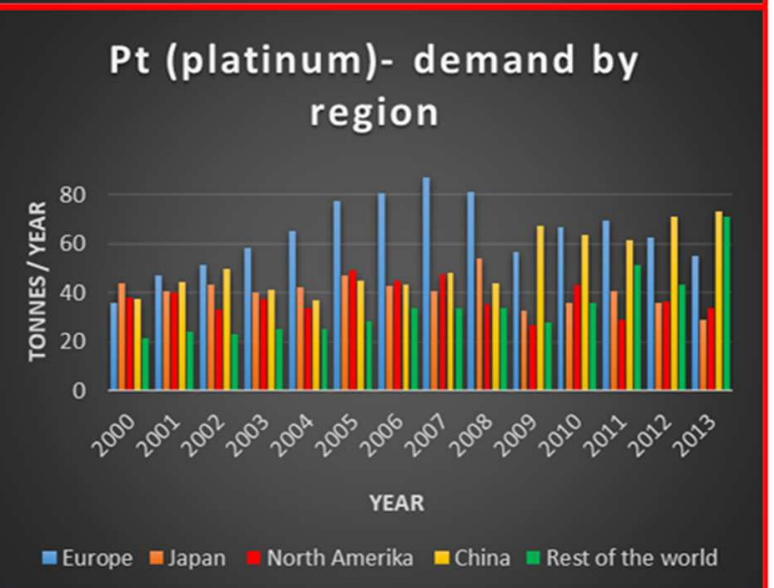

- South Afrika $\quad$ Rusia North Amerika $\quad$ Zimbabwe $\quad$ Others

Figure 5 Platinum, palladium, and rhodium supply (a) and demand (b) by region and their development since 2000 Data source [13]

A somewhat similar case, even more drastic, can be found around rare-earth elements. The element cerium is of interest in this context due to its utilization in the wash coats of catalysts. By 2005, China accounted for $96 \%$ of global rare earth production, including more than $99 \%$ of heavy rare earth oxides. In 2008, the production of rare-earth elements peaked, accounting for $97 \% 4$ of global production. Slowly, the rest of the world is trying to open new resources to become more independent, but the chemistry is complex, and the rest of the world will have its main impact on light rare earths, like cerium, and not on the heavy ones, where a strong dependence will remain.

A second reason for price peaks is the fact that, as shown in Figure 5, the main utilization area of platinum and palladium as well as cerium and rhodium is the automotive industry in form of catalytic converters. Statistical data show that around 55\% of palladium and platinum are used in automotive catalysts $(40 \%$ 
of Pt and $67 \%$ of $\mathrm{Pd}$ ), which makes it clear why the supply is strongly dependent on the automotive market [12].

\section{Results and discussion}

Initially, uncontrolled oxidation and reduction catalysts were used in mixture preparation equipment without electronic control. The advent of electronics brought with it a more precise regulation of the composition of the mixture with the advent of a three-way oxidation-reduction catalyst. The catalyst with a ceramic support used mainly due to the low price is in decline. Today, a metal-supported catalyst is increasingly preferred.

With the ever-tightening legislation on emission limits and the position of the automotive industry, there is a growing interest in new catalysts, and so is the consumption of platinum, palladium and radio. Due to the yield of these metals obtained by recycling catalysts, it is economically advantageous to thus obtain platinum metals from spent catalysts. These represent a significant secondary source of precious metals.

Within Central Europe and the European area, in connection with the creation of this article, it was not possible to find a suitable database that would specify the purchase and consequence of the recycling of car catalytic converters from ordinary users. The Slovak Republic and its statistical office do not keep a database on the purchase of catalysts. This fact is slightly worrying about the environment. On the positive side, there is a company on the world market that has developed the Eco Cat application, where the application, with its 20,000 different catalysts that have been inventoried and awarded so far, is an ever-growing database that is fast becoming the search standard for the industry. The Ecotrade Group has been a recognized leader in the ecological and ethical recycling of catalysts in Asia for more than 15 years, using state-of-theart recycling technologies and a huge network of industrial partners.

Hydrometallurgical and pyrometallurgical methods are used among the existing methods of recovering noble metals from depleted catalysts.

There is currently an effort to develop new methods for recycling and separating precious metals.

\section{Acknowledgement}

The submitted paper is a part of EIT RM KAVA 20220 PHEIDIAS project, "PHEIDIAS - An Innovative Hydrometallurgical Recycling System for PGMs Recovery".

\section{References}

[1] KONČALOVÁ, A., DUBCOVÁ, A.: Význam recyklácie v odpadovom hospodárstve, Geographia Cassoviensis IV., Vol. 2010, No. 2, pp. 56-61, 2010. (Original in Slovak)

[2] XUN, D., HAO, H., SUN, X., LIU, Z., ZHAO, F.: Endof-life recycling rates of platinum group metals in the automotive industry: Insight into regional disparities, Journal of Cleaner Production, Vol. 266, No. September, 2020. doi:10.1016/j.jclepro.2020.121942

[3] ASIMELLIS, G., MICHOS, N., FASAKI, I., KOMPITSAS, M.: Platinum group metals bulk analysis in automobile catalyst recycling material by laser-induced breakdown spectroscopy, Spectrochimica Acta Part B: Atomic Spectroscopy, Vol. 63, No. 11, pp. 1338-1343, 2008.

[4] DING, Y., ZHENG, H., ZHANG, S., LIU, B., WU, B., JIAN, Z.: Highly efficient recovery of platinum, palladium, and rhodium from spent automotive catalysts via iron melting collection, Resources, Conservation and Recycling, Vol. 155, No. April, 2020.

[5] DA SILVA, L., DE ALMEIDA, R., SILVA FAUSTINO, V., JÚNIOR, P.: Recycling of the platinum of vehicle catalysts at end of life, $S A E$ Technical paper, Vol. 2018, pp. 1-9, 2018. doi:10.4271/2018-36-0106

[6] CHUAN, L., SUN, S., ZHU, X., TU, G.: Platinum Recovery from Hydrometallurgical Residue of Waste Automotive Catalysts Processing by HighTemperature Smelting Process, Mining Metallurgy \& Exploration, Vol. 38, No. 53-57, pp. 1-13, 2020.

[7] FAKTOR, I.: Cesné vozidlá III, Expol pedagogika spol. s.r.o., Bratislava, 2004. (Original in Slovak)

[8] VRLÍKOVÁ, D.: Spracovanie automobilových katalyzátorov, Diploma Thesis, 2012. (Original in Slovak)

[9] KRAUS, M.: Katalyzátory kolem nás, Academia Praha, 1982. (Original in Czech)

[10] KRIŠTOFOVÁ, D.: Recyklace neželaných kovú, VŠB- TU Ostrava, 2006. (Original in Czech)

[11] SIKOROVÁ, L., LIČBINSKÝ, R., ADAMEC, V.: Platinové kovy $\mathrm{z}$ automobilových katalyzátorov v životnom prostredí, Chemické listy, Vol. 105, pp. 361-366, 2011. (Original in Czech)

[12] STEINLECHNER, S., ANTREKOWITSCH, J.: Potential of a Hydrometallurgical Recycling Process for Catalysts to Cover the Demand for Critical Metals, Like PGMs and Cerium, JOM, Vol. 67, No. February, pp. 406-411, 2015.

[13] MATTHEY, J.: Market Data Tables, Hertfordshire, U.K., Johnson Matthey Precious Metals Management, [Online], Available: www.platinum.m atthey.com/publications/market-data-tables [25 Aug 2021], 2021.

[14] KAČMÁRY, P., STRAKA, M.: Statistical development of transport which reflects the need for catalysts, Acta Tecnología, Vol. 6, No. 4, pp. 123127, 2020. doi:10.22306/atec.v6i4.97

Review process

Single-blind peer review process. 